\title{
Changes in serum prolactin level during intracytoplasmic sperm injection, and effect on clinical pregnancy rate: a prospective observational study
}

\author{
Ahmed Kamel ${ }^{1 *}\left(\mathbb{D}\right.$, Ayman A. Halim', Mohamed Shehata², Salwa AlFarra', Yahia El-faissal', Wafaa Ramadan ${ }^{1}$
} and Ahmed M. Hussein ${ }^{1}$

\begin{abstract}
Background: Transient hyperprolactinemia was proven to adversely affect the outcome of IVF. We aimed to identify changes in serum prolactin levels in patients undergoing ICSI, and to evaluate the effect of these changes on the clinical pregnancy rate.

Methods: A prospective observational study included 90 patients scheduled for ICSI cycles. In each case 4 serum samples were collected during the cycle (midluteal, before ovum pick up procedure (OPU), $2 \mathrm{~h}$ after OPU, and before embryo transfer). Serum prolactin level was determined by immunoassay each time.

Results: The sample collected $2 \mathrm{~h}$ after OPU had a mean difference of $25.8 \pm 2.8 \mathrm{ng} / \mathrm{ml}$ compared to the basal serum prolactin $(p<0.01)$. In comparison to other samples, this highlighted a significant hyperprolactinemia occurring after OPU, and resolving before embryo transfer. No statistically significant difference between the different serum prolactin samples amongst the pregnant and non pregnant patients. There was a significant positive pearson correlation between the prolactin levels before OPU, and the presence of higher quality embryos $(r=0.274, p=0.019)$.
\end{abstract}

Conclusion: In normoprolactinemic women transient hyperprolactinemia is identified in patients undergoing ICSI, and it doesn't affect the clinical pregnancy rates. A positive correlation was identified between higher quality embryos, and serum prolactin level before OPU.

Trial registration: ClinicalTrials.gov Identifier: NCT02292953, First received: November 10, 2014.

Keywords: Embryo quality, Intracytoplasmic sperm injection, Hyperprolactinemia, Prolactin

\section{Background}

Prolactin (PRL) is a 198 amino acid polypeptide hormone secreted in a pulsatile manner from the anterior pituitary, and is synthesized by lactotroph cells. It weighs $23 \mathrm{kDa}$, and its secretion is affected by many factors which include stress, sleep, pregnancy, ingesting food, and chest wall stimulation (trauma, or pain). Prolactin has a primary role in the regulation of reproductive functions. While the elevation of its level beyond normal (hyperprolactinemia)

\footnotetext{
* Correspondence: dr.ahmed.m.kamel@gmail.com

'Obstetrics and Gynecology Department, Cairo University, P.O. Box: 11562,

KasrAlainy St., Garden City, Cairo, Egypt

Full list of author information is available at the end of the article
}

can be either physiological, pathological, or idiopathic; its clinical manifestations can vary from severe to none [1].

Prolactin receptors have been found on endometrial cells. The secretion of endometrial prolactin helps in maintaining endometrial receptivity, and has been shown to provide an optimal environment for the implanting blastocyst transferred during in-vitro fertilization (IVF) cycles. A high enough prolactin level can inhibit the proliferation of luteinizing granulosa cells, and can also interfere with corpus luteum function resulting in luteal phase defect, as well as abnormal implantation, and embryo development [2]. Different studies have proven the existence of a state of hyperprolactinemia during IVF/Intracytoplasmic sperm injection (ICSI) cycles [3, 4]. 
Transient hyperprolactinemia has been proven to adversely affect the outcome of IVF, and studies have concluded that patients with normal serum prolactin levels had higher fertilization and cleavage rates [5-7]. While other researchers found the effect of increased serum prolactin during IVF to be insignificant [8-10], subsequent studies [11-14] found a positive effect of transient hyperprolactinemia on the outcome of ovarian simulation in IVF.

The aim of this study was to identify changes in serum prolactin levels in patients undergoing ICSI, and to evaluate the effect of these changes on the clinical pregnancy rate.

\section{Methods}

\section{Experimental design \& sample size}

An internal review board "The Scientific \& Ethics committee" of the OBGYN department, Cairo University approved this study protocol on the fifth of October 2014. One hundred two normo-prolactinemic patients were recruited in the study while attending the assisted reproduction clinic in Kasr Alainy, Cairo university hospital. All enrolled subjects were already scheduled for ICSI. Each participant was subjected to investigations which included follicle stimulating hormone $(\mathrm{FSH})$, Luteinizing hormone $(\mathrm{LH})$, thyroid stimulating hormone (TSH), prolactin, and semen analysis for the husband.

The sample size was calculated using an online calculator [15] where the measured outcome was the difference of serum prolactin levels between samples. The confidence level was set at $95 \%$, and the margin of error at $10.4 \%$, in a $50 \%$ response distribution, giving us 90 patients in a population more than 20,000.

Inclusion Criteria for the study included an age range between 20 and 38 years, women with either 1ry or 2ry infertility scheduled for ICSI. Exclusion from the study was due to hyperprolactinemia (high basal serum prolactin), uterine anomalies, repeated ICSI failure (3 or more failed trials), embryo transfer beyond day 3 , frozen thawed cycles, or had any contraindications for pregnancy (serious uncontrolled medical diseases such as diabetes, heart disease, hypertension, or ovarian tumors (cancer of any location). Patients were also excluded if they were on any medication that is known to alter prolactin levels e.g. antipsychotics and risperidone, or had a history of thyroid dysfunction (e.g. low TSH), or had any medical disorders that affect serum prolactin e.g. acromegaly and chronic renal failure.

After applying inclusion and exclusion criteria, the patients were scheduled to start ICSI cycle at Kasr Alainy assisted reproduction unit. Patient counseling and informed consent was taken regarding all blood samples that will be drawn, and permission for publishing this data was granted.

The first baseline serum prolactin level was recorded in the mid-luteal phase of the cycle preceding ICSI. The second blood sample was taken in operating room just before induction of anesthesia for OPU. A Third blood sample was taken two hours after aspiration of the last follicle in recovery room post-operatively. A Fourth and final blood sample was taken before embryo transfer. To avoid fluctuations in serum prolactin levels, all OPU and embryo transfers (ET) was scheduled at 9:00 am after fasting for $8 \mathrm{~h}$. The blood samples were immediately sent to central laboratory of Kasr Alainy Cairo university hospital after retrieval. Serum prolactin was analyzed each time though immunoassay by ADVIA Centaur Immunoassay System (CP Immunoassay System •, SIEMENS AG, Munich, Germany).

\section{Intracytoplasmic sperm injection}

The standard long gonadotrophin-releasing hormone $(\mathrm{GnRH})$ agonist protocol was used for all patients where $0.1 \mathrm{mg}$ of Triptorelin daily S.C injection (Decapeptyl ${ }^{\circ} \mathrm{FER}$ RING PHARMACEUTICALS, Switzerland) was applied from the mid-luteal phase onward till the day of human chorionic gonadotropin (hCG) injection. When the serum estradiol (E2) level was $<50 \mathrm{pg} / \mathrm{ml}$, gonadotropins in the form of human menopausal gonadotropin (HMG) (Merional ${ }^{\oplus}$, IBSA, InstitutBiochimique SA, Lugano, Switzerland) were given IM from the 3rd day of menstruation. The starting dose of HMG was set from 150 to 300 IU according to the patient's age, basal FSH level, antral follicular count (AFC), and body mass index (BMI).

The stimulation was monitored by transvaginal ultrasonography, and serial E2 measurements starting from the seventh day of the cycle, and the HMG dose was adjusted individually according to follicular response. After the development of three or more follicles $\geq 18 \mathrm{~mm}, 10,000$ unit of hCG (Choriomon, IBSA, Institut Biochimique SA) was given IM, and trans-vaginal ultrasound guided ovum pick up procedure (OPU) was scheduled $36 \mathrm{~h}$ later. ICSI was performed as described by Mansour et al. [16].

Progesterone $100 \mathrm{mg}$ IM daily injections (Prontogest ${ }^{\bullet}$ IBSA, InstitutBiochimique SA, Lugano, Switzerland) were given as luteal support starting from the day of ET, and continued for 16 days. Pregnancy was recorded when $\beta$ HCG > 10 IU on day 14 after ET, and a second higher value $48 \mathrm{~h}$ later. This was followed by ultrasonography for confirmation of fetal pole and cardiac activity at 7 weeks of gestation.

Descriptive data such as age, cause and type of infertility, the number of oocytes retrieved at OPU, and embryo grading were recorded as well as the result of every serum prolactin sample. 


\section{Statistical analysis}

Continuous data were expressed as mean \pm SD $(95 \%$ confidence interval $[\mathrm{CI}]$ ), and were compared using Student $t$ test or Mann-Whitney U test as appropriate. General linear model for repeated measures was used to evaluate the mean pair wise comparison between different prolactin levels where Bonferroni adjustment was used in the estimated marginal means. Correlation between various variables was done using Pearson moment correlation equation. Statistical analysis was performed using the Statistical Package for the Social Sciences program, v20.0 (SPSS Inc., Chicago, IL, USA). A two-tailed $P$ value $<0.05$ was considered statistically significant.

\section{Results}

The total number of participants in our study was 102 patients. During the course of our study twelve cases were excluded as the embryo transfer procedure was cancelled. Three of cancelled cases were identified as high risk for ovarian hyperstimulation, and had their embryos frozen for transfer in another cycle. In four cases, no oocytes were retrieved, and in another four cases only germinal vesicles (GV) were retrieved, and not injected. There was a single case of failed fertilization. Recruitment then continued till 90 patients were enrolled.

\section{Descriptive data}

33 patients out of 90 got pregnant (36\%), only 27 of which were clinical pregnancies, giving us $30 \%$ clinical pregnancy rate. The implantation rate was $19.3 \%$, and the live birth rate was $23.3 \%$. Primary infertility represented $61.1 \%$ of cases, tubal factor comprised $40 \%$ of the cases, unexplained infertility was $26.6 \%$, male factor was $20 \%$, and unovulatory polycystic ovarian syndrome (PCOS) was $13.4 \%$. Endometriosis was identified in $17 \%$ of cases with tubal factor.

Descriptive statistics are illustrated in Table 1, where the ovarian reserve of the participants appears normal as denoted by the AFC, serum FSH and LH. The mean BMI was $29.1 \pm 1.5 \mathrm{~kg} / \mathrm{m}^{2}$, and there was no statistical significance in the BMI between the patients that got pregnant and those that didn't $(p=0.846)$.

\section{Transient hyperprolactinemia}

The mean level of prolactin before OPU was within the normal range, while the level after OPU was elevated beyond normal reaching a maximum of $93.2 \mathrm{ng} / \mathrm{ml}$. However the mean levels of PRL before embryo transfer did fall back to normal levels and a maximum value of $73.6 \mathrm{ng} / \mathrm{ml}$ was recorded.

The difference between the mean basal prolactin levels and the other serum samples collected is shown in Table 2. The sample collected $2 \mathrm{~h}$ after OPU had a statistically significant mean difference of $25.8 \pm 2.8 \mathrm{ng} / \mathrm{ml}$ in comparison to the basal level of serum prolactin $(p<$ $0.01)$. This helps highlight a significant hyperprolactinemia occurring after OPU, and resolving before embryo transfer. There was no statistical difference between the other samples, and the basal prolactin level as shown in Table 2.

Table 1 Descriptive statistics showing different hormone levels \& factors affecting ICSI outcome

\begin{tabular}{llll}
\hline & Minimum & Maximum & Mean \pm SD \\
\hline Age (years) & 20 & 38 & $29.6 \pm 5.4(28.7-30.6)$ \\
AFC (follicles) & 2 & 32 & $13 \pm 6.3(11.7-14.4)$ \\
FSH (IU/mL) & 1.89 & 16.4 & $6 \pm 2.9(6-7.2)$ \\
LH (IU/mL) & 1.1 & 13.9 & $5.2 \pm 2.8(4.7-5.8)$ \\
TSH $(\mathrm{mlU} / \mathrm{L})$ & 0.7 & 4.1 & $2.01 \pm 0.84(1.83-2.18)$ \\
BMI $\left(\mathrm{kg} / \mathrm{m}^{2}\right)$ & 25.1 & 33 & $29.1 \pm 1.5(28.8-29.4)$ \\
Basal PRL level $(\mathrm{ng} / \mathrm{ml})$ & 1.1 & 28 & $13.7 \pm 6.6(12.3-15.1)$ \\
PRL before OPU $(\mathrm{ng} / \mathrm{ml})$ & 0.4 & 46.2 & $16.8 \pm 11.6(14.4-19.2)$ \\
PRL after OPU (ng/ml) & 0.5 & 93.2 & $39.5 \pm 25.4(34.2-44.8)$ \\
PRL before ET $(\mathrm{ng} / \mathrm{ml})$ & 0.1 & 73.6 & $11.5 \pm 10(9.4-13.6)$ \\
Number of oocytes retrieved in OPU & 2 & 44 & $17.3 \pm 10.7(15-19.5)$ \\
Number of metaphase $\|$ oocytes & 1 & 13 & $5.7 \pm 2.9(5.1-6.4)$ \\
Fertilization rate $(\%)$ & 40 & 100 & $81.5 \pm 16(78.2-85)$ \\
Number of embryos transferred & 1 & 5 & $3.2 \pm 1.1(3-3.4)$ \\
Number of high quality embryos & 0 & 5 & $2.9 \pm 1.3(2.6-3.1)$ \\
Number of low quality embryos & 0 & 2 & $1.1 \pm 0.3(1-1.2)$ \\
\hline
\end{tabular}

Values are given in given in numbers, \& mean \pm SD $(95 \% \mathrm{Cl})$

SD standard deviation 
Table 2 The mean difference between different levels of serum prolactin compared to the basal level

\begin{tabular}{|c|c|c|c|c|c|}
\hline & \multirow[t]{2}{*}{ Mean Prolactin level ng/ml } & \multirow{2}{*}{$\begin{array}{l}\text { Mean } \\
\text { difference } \\
\text { from basal } \\
\text { PRL level } \\
\mathrm{ng} / \mathrm{ml}\end{array}$} & \multicolumn{2}{|c|}{ 95\% confidence interval } & \multirow[t]{2}{*}{$p$-value } \\
\hline & & & Lower bound & Upper bound & \\
\hline PRL before OPU & $16.8 \pm 11.6$ & $3.1 \pm 1.4$ & 0.556 & 6.816 & 0.146 \\
\hline PRL after OPU & $39.5 \pm 25.4$ & $25.8 \pm 2.8$ & 18.205 & 33.391 & $<0.01^{*}$ \\
\hline PRL before ET & $11.5 \pm 10$ & $2.2 \pm 1.1$ & 0.852 & 5.29 & 0.326 \\
\hline
\end{tabular}

Values are given as mean \pm standard error $(95 \% \mathrm{Cl})$

*Statistically significant result $p<0.05$

$(\mathrm{F}=406.9, p<0.001)$

Table 3 compares the mean prolactin levels between patients who had a clinical pregnancy to those who didn't. There was also no statistically significant difference between the different prolactin samples amongst the two groups even though there was a statistically significant rise in serum prolactin in the sample taken $2 \mathrm{~h}$ after OPU.

Relationship between PRL samples and other parameters Table 4 shows a statistically significant positive pearson correlation between the prolactin level before OPU, and the number of higher quality embryos $(p=0.019)$. Higher quality embryos were defined as embryos with equal blastomeres, and fragmentation less than 30\%. Figure 1 shows a scatter plot which illustrates the correlation between high quality embryos and serum PRL before OPU. There were no other correlations between the remaining prolactin samples, and higher, or lower quality embryos (unequal blastomeres, fragmentation `30\%, multinucleation or other cytoplasmic defects).

There was also a statistically significant negative relationship between the number of oocytes retrieved, and serum prolactin level before embryo transfer as shown by pearson correlation. The same sample also showed a statistically significant positive correlation with fertilization rate. There were no other significant correlations between any other serum prolactin sample and fertilization rate, or the number of oocytes retrieved. The clinical application of this correlation is not of value, as chronologically the number of oocytes retrieved is already known, and the fertilization rate can be calculated before this sample can be drawn at a later time (before ET).

\section{Discussion}

Serum prolactin levels vary in the body according to different stimuli, including sleep, pregnancy, stress, chest

Table 3 Comparison between the clinical parameters, and mean levels of serum prolactin in the pregnant and non pregnant groups

\begin{tabular}{|c|c|c|c|}
\hline & Pregnant & Non pregnant & $P$-value \\
\hline Age (years) & $29.2 \pm 6(26.9-31.6)$ & $29.8 \pm 5.2(28.7-31.1)$ & 0.644 \\
\hline AFC (follicles) & $15.1 \pm 7.2(12.3-17.9)$ & $12.1 \pm 5.7(10.7-13.5)$ & 0.101 \\
\hline $\mathrm{FSH}(\mathrm{IU} / \mathrm{mL})$ & $7 \pm 3.4(5.7-8.3)$ & $6.4 \pm 2.6(5.8-7.1)$ & 0.403 \\
\hline $\mathrm{LH}(\mathrm{IU} / \mathrm{mL})$ & $5.5 \pm 2.6(4.5-6.6)$ & $5.1 \pm 2.9(4.4-5.8)$ & 0.487 \\
\hline $\mathrm{TSH}(\mathrm{mlU} / \mathrm{L})$ & $2.10 \pm 0.84(1.78-2.43)$ & $1.96 \pm 0.84(1.75-2.18)$ & 0.467 \\
\hline $\mathrm{BMI}\left(\mathrm{kg} / \mathrm{m}^{2}\right)$ & $29.1 \pm 1.4(28.5-29.6)$ & $29.1 \pm 1.5(28.7-29.5)$ & 0.853 \\
\hline Basal PRL level (ng/ml) & $12.8 \pm 6.5(10.3-15.3)$ & $14.1 \pm 6.8(12.4-15.8)$ & 0.414 \\
\hline PRL before OPU (ng/ml) & $15.7 \pm 11.2(11.4-20.1)$ & $17.3 \pm 11.8(14.3-20.3)$ & 0.551 \\
\hline PRL after OPU (ng/ml) & $35.2 \pm 25.4(25.4-45.1)$ & $41.4 \pm 25.4(35-47.8)$ & 0.286 \\
\hline PRL before ET (ng/ml) & $9.7 \pm 7.6(6.7-12.6)$ & $12.3 \pm 10.9(9.5-15)$ & 0.254 \\
\hline Number of oocytes retrieved in OPU & $22.8 \pm 9.6(19.1-26.6)$ & $14.8 \pm 10.3(12.2-17.4)$ & $0.001^{*}$ \\
\hline Number of metaphase II oocytes & $7.3 \pm 2.6(6.3-8.3)$ & $5.1 \pm 2.8(4.4-5.8)$ & $0.001^{*}$ \\
\hline Fertilization rate (\%) & $82 \pm 13.1(76.87-87.03)$ & $81.4 \pm 17.2(77-85.7)$ & 0.954 \\
\hline Number of embryos transferred & $3.7 \pm 0.7(3.4-4)$ & $3 \pm 1.1(2.7-3.2)$ & $0.001^{*}$ \\
\hline Number of high quality embryos & $3.5 \pm 6.9(3.1-3.8)$ & $2.6 \pm 1.3(2.3-2.9)$ & $0.002^{*}$ \\
\hline Number of low quality embryos & $1.2 \pm 0.4(0.8-1.6)$ & $1.1 \pm 0.2(0.9-1.2)$ & 0.391 \\
\hline
\end{tabular}

Values are given as mean \pm SD $(95 \% \mathrm{Cl})$

*Statistically significant result $p<0.05$ 
Table 4 Correlation between serum prolactin levels, embryo quality \& fertilization rate

\begin{tabular}{|c|c|c|c|c|c|c|c|c|}
\hline & \multicolumn{2}{|c|}{ Higher quality embryos } & \multicolumn{2}{|c|}{ Lower quality embryos } & \multicolumn{2}{|c|}{ Number of retrieved oocytes } & \multicolumn{2}{|c|}{ Fertilization rate } \\
\hline & $\overline{P C}$ & $p$-value & $\overline{P C}$ & $p$-value & $\overline{P C}$ & $p$-value & $\overline{P C}$ & $\overline{p \text {-value }}$ \\
\hline Basal PRL level & -0.182 & 0.085 & 0.108 & 0.607 & -0.119 & 0.264 & 0.065 & 0.541 \\
\hline PRL before OPU & 0.274 & $0.019^{*}$ & 0.245 & 0.237 & -0.004 & 0.972 & 0.044 & 0.680 \\
\hline PRL after OPU & 0.108 & 0.310 & 0.306 & 0.136 & -0.135 & 0.205 & -0.081 & 0.446 \\
\hline PRL before ET & -0.117 & 0.272 & 0.093 & 0.093 & -0.218 & $0.039^{*}$ & 0.228 & $0.030^{*}$ \\
\hline
\end{tabular}

"Statistically significant result $p<0.05$

PC Pearson Correlation

wall stimulation, food ingestion, and trauma. Stress has been shown to be a common cause for raising serum prolactin levels [1]. This may explain the significant rise in serum PRL after OPU. Many studies has documented the poor effect stress has on the success of IVF/ICSI [17-20]. Our study has clearly documented a state of transient hyperprolactinemia which was also documented by other authors [3, 4].

This rise in serum prolactin peaked after the ovum pickup procedure with some readings reaching a maximum recorded value of $93.2 \mathrm{ng} / \mathrm{ml}$, but returning to normal levels before ET.

Boyers et al. [4] had similar results where the mean basal level of serum prolactin was comparable to ours. They had a mean increase in serum prolactin during OPU reaching values higher than we recorded. The level decreased after OPU but remained above the baseline.
Their results also showed a return of serum prolactin to normal before embryo transfer.

Our results showed that elevated serum prolactin identified after OPU had no significant impact on pregnancy, as did the results from previous work by Doldi et al. [21] This was contradictory to the work presented by Zhong et al. [3] which stated that the rise in serum prolactin level $\geq 90 \mathrm{ng} / \mathrm{ml}$ dramatically affected pregnancy rate, by modulating the hypothalamo-pituitary ovarian axis, corpus luteum function and endometrial receptivity. Other studies [8-10] had findings similar to our own, confirming the presence of hyperprolactinemia without recording any deleterious effects on pregnancy.

In the study by Doldi et al. [21] they divided the patients into two groups and attempted to treat hyperprolactimenia in one group with cabergoline (Dostinex; pharmacia and Upjohn; $500 \mu \mathrm{g}$ per week), or bromocriptine (Parlodel ${ }^{\circledR}$;

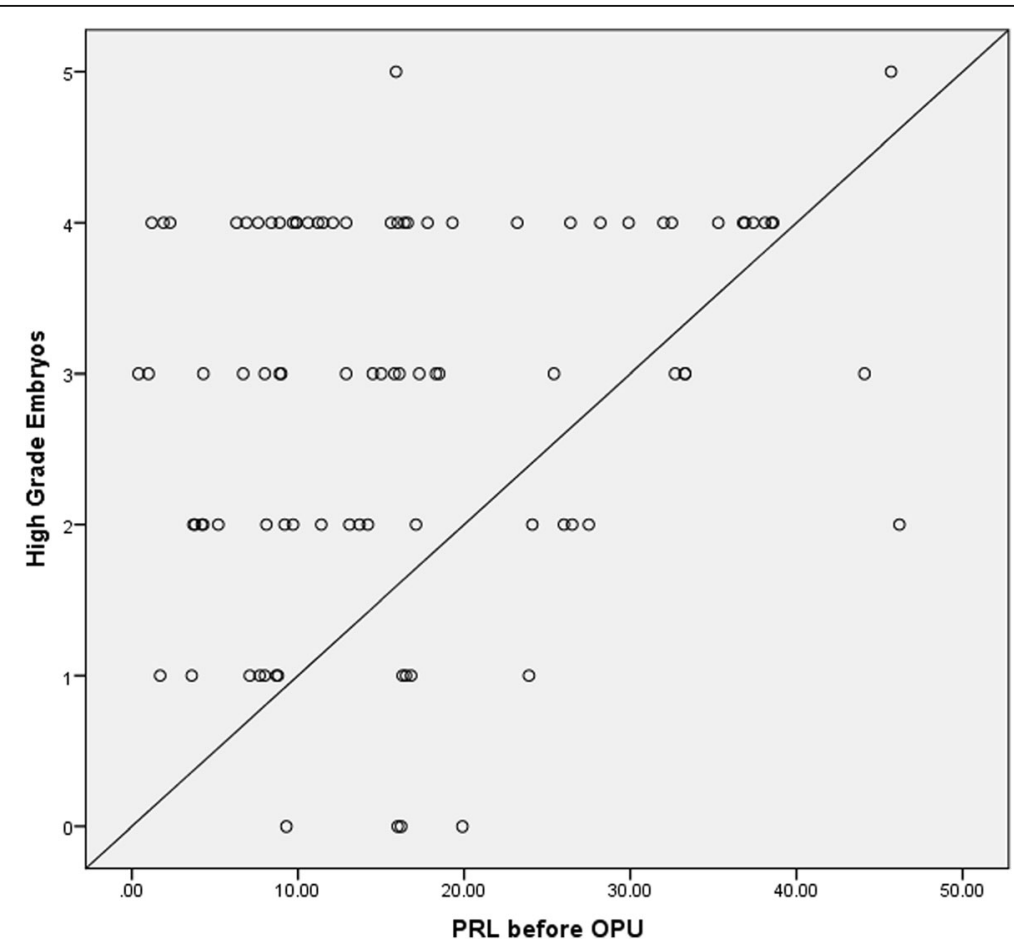

Fig. 1 Scatter plot showing correlation between serum prolactin levels before OPU and high quality embryos 
Novartis; $2.5 \mathrm{mg}$ per week), and placebo in the control group. The treatment started prior to ovarian stimulation, and continued till there was a decrease in plasma prolactin levels, and eventually they found no significant difference in the pregnancy rate.

We also found a positive correlation between higher quality embryo and the serum prolactin sample taken before OPU. This can theoretically help predict better embryo implantation and successful pregnancy, however the same sample failed to show statistical significance when it came to clinical pregnancy. Mendoza et al. [11] concluded that better quality oocytes and embryos resulted from follicles with higher steroid and prolactin levels.

Keeping in mind that the development of high quality embryos requires good quality oocytes, the presence of prolactin receptors or it mRNA has been detected in the matured oocyte, and its surrounding cumulus cells. Evidence also suggests that it participates in the development, and maturation of oocytes [22]. Hypoprolactinemia was reported to decrease cleavage and pregnancy rates [23]. Jinno et al. [24] studied the effect of giving bromocriptine in the cycle preceding IVF, and found that they had higher cleavage, fertilization, and pregnancy rates. They also reported a higher proportion of high quality embryos. This was attributed to better oocyte maturation which was achieved due to the rebound increase of prolactin after the discontinuation of bromocriptine, which restored post receptor responsiveness in granulosa cells. Moride et al. [25] also concluded that the bromcriptine rebound method yielded morphologically better embryos.

Zhong et al. [3] presented results stating that a higher prolactin level at the day of hCG trigger yielded more oocytes by showing a positive spearman correlation while failing to show prolactin in a multiple linear regression analysis equation, concluding that serum prolactin at the day of pick up cannot predict the number of oocytes retrieved. They also showed no marked difference in the fertilization rate. Our study showed no correlation between the serum prolactin samples drawn, and either fertilization rate or the number of oocytes retrieved in the 1st three samples.

However our study demonstrated in the sample taken before embryo transfer, a statistically significant positive pearson correlation with fertilization rate, and a negative relationship with the number of oocytes retrieved. Optimizing these results for clinical value is doubtful as the final serum prolactin sample is taken before embryo transfer, and so if any benefit is to come from their value, the sample has to predate the oocyte retrieval process or the fertilization procedure.

Some of the limitations to our study included not identifying a cut off value for PRL sample before OPU in predicting higher quality embryos. This finding was a secondary outcome, and couldn't be predicted before the statistical analysis of the results. The inclusion criteria was not specific enough to exclude all causes of low cleavage rates, and poor embryo quality e.g. older age, low ovarian reserve, PCOS, and endometriosis, which may lead to bias, and low accuracy if receiver operating characteristic (ROC) analysis was done to determine a cut off value.

\section{Conclusions}

In normoprolactinemic women a state of transient hyperprolactinemia is clearly identified in patients undergoing ICSI. Although its cause is not identified, it can be attributed to stress and anxiety. This increase appears to be harmless, and doesn't affect the outcome of ICSI. A significant positive correlation was identified between higher quality embryos and prolactin before ovum pickup. More research is warranted to help increase the predictability of better quality embryos, and hence quantification of their implantation potential. This might help with embryo selection aiming at smaller number of embryos to be transferred per cycle, with a consequent decrease in the risk of multiple pregnancies without decreasing pregnancy rates.

\section{Abbreviations \\ AFC: Antral follicle count; AUC: Area under the curve; BMI: Body mass index E2: Estradiol; ET: Embryo transfer; FSH: Follicle stimulating hormone; \\ $\mathrm{GnRH}$ : Gonadotrophin-releasing hormone; hCG: human chorionic gonadotropin; HMG: Human menopausal gonadotropin; ICSI: Intracytoplasmic sperm injection; IVF: In vitro-fertilization; OPU: Ovum pick up procedure; PC: Pearson correlation; PCOS: Polycystic ovary syndrome; PRL: Prolactin; ROC: Receiver operating characteristic; $\beta$-HCG: beta chorionic gonadotrophin}

\section{Funding}

This work was funded by Cairo University, and they had no role or influence in conducting the actual work.

\section{Availability of data and materials}

The datasets used and/or analysed during the current study are available from the corresponding author on reasonable request.

\section{Authors' contributions}

The idea was conceived and study design was made by AK \& AAH. The clinical aspect (folliculometry, ovum pick \& embryo transfer) of the study was done by AK \& SA. MS was responsible for supervising sample collection and lab work. SA did all data collection. YEF, AMH and WR revised the collected data and did the statistics. Drafting was written by $\mathrm{AK}$ and $\mathrm{AMH}$, revision was done by WR \& MS. Final approval \& revision by AAH \& YEF. All authors read and approved the final manuscript.

Authors' information

All authors of this work have years of experience in the field of ART.

\section{Ethics approval and consent to participate}

The Scientific \& Ethics committee of Cairo University's OBGYN department approved this study, and permission to the conduct the study was granted by the assisted conception unit of Kasr Alainy hospital. All participants in the study signed a written informed consent.

\section{Competing interests}

The authors of this study declare no conflict of interest and no competing interests with respect to the research, authorship, and publication of this article. 


\section{Publisher's Note}

Springer Nature remains neutral with regard to jurisdictional claims in published maps and institutional affiliations.

\section{Author details}

'Obstetrics and Gynecology Department, Cairo University, P.O. Box: 11562 KasrAlainy St., Garden City, Cairo, Egypt. ${ }^{2}$ Clinical and Chemical Pathology Department, Cairo University, Cairo, Egypt.

Received: 17 May 2016 Accepted: 26 April 2018

Published online: 09 May 2018

\section{References}

1. Majumdar A, Mangal NS. Hyperprolactinemia. J Hum Reprod Sci. 2013;6(3): 168-75.

2. Chawla R, Antonios T, Berhanu E, Ayana G. Detection of Macroprolactinemia and molecular characterization of prolactin isoforms in blood samples of hyperprolactinemic women. In: Journal of medical biochemistry, vol. 31; 2012. p. 19.

3. Y-p Z, Shen X-t, Ying Y, Wu H-T, Li J, Qi Q, Zhou C-Q, Zhuang G-L. Impact of transitory hyperprolactinemia on clinical outcome of in vitro fertilization and embryo transfer. In: Journal of medical biochemistry, vol. 31; 2012. p. 27.

4. Boyers SP, Lavy G, Russell JB, Polan ML, DeCherney AH. Serum prolactin response to embryo transfer during human in vitro fertilization and embryo transfer. J In Vitro Fert Embryo Transf. 1987;4(5):269-72.

5. Huang KE, Bonfiglio TA, Muechler EK. Transient hyperprolactinemia in infertile women with luteal phase deficiency. Obstet Gynecol. 1991; 78(4):651-5.

6. Reinthaller A, Deutinger J, Csaicsich P, Riss P, Muller-Tyl E, Fischl F, Janisch H. Effect of serum prolactin on cycle stimulation and fertilization of human oocytes. Geburtshilfe Frauenheilkd. 1987;47(4):246-8.

7. del Pozo E. Management of borderline hyperprolactinemia. Horm Res. 1985; 22(3):204-8.

8. Chang SP, Ng HT, Lan TL, Chao HT, Wei TC, Yang TS, Ou-Yang XR. Transient hyperprolactinemia in gonadotropin-stimulated cycles for in vitro fertilization and its effect on conception. Zhonghua Yi Xue Za Zhi. 1993; 51(6):401-6. Free China ed

9. Pattinson HA, Taylor PJ, Fleetham JA, Servis SA. Transient hyperprolactinemia has no effect on endocrine response and outcome in in vitro fertilization (IVF). J In Vitro Fert Embryo Trans. 1990;7(2):89-93.

10. Hummel WP, Clark MR, Talbert LM. Transient hyperprolactinemia during cycle stimulation and its influence on oocyte retrieval and fertilization rates. Fertil Steril. 1990;53(4):677-81.

11. Mendoza C, Cremades N, Ruiz-Requena E, Martinez F, Ortega E, Bernabeu S, Tesarik J. Relationship between fertilization results after intracytoplasmic sperm injection, and intrafollicular steroid, pituitary hormone and cytokine concentrations. Hum Reprod. 1999;14(3):628-35.

12. Jinno M, Katsumata Y, Hoshiai T, Nakamura Y, Matsumoto K, Yoshimura Y. A therapeutic role of prolactin supplementation in ovarian stimulation for in vitro fertilization: the bromocriptine-rebound method. J Clin Endocrinol Metab. 1997:82(11):3603-11.

13. Jinno M, Yoshimura Y, Ubukata Y, Nakamura Y. A novel method of ovarian stimulation for in vitro fertilization: bromocriptine-rebound method. Fertil Steril. 1996;66(2):271-4.

14. Kamel MA, Zabel G, Bernart W, Neulen J, Breckwoldt M. Comparison between prolactin, gonadotrophins and steroid hormones in serum and follicular fluid after stimulation with gonadotrophin-releasing hormone agonists and human menopausal gonadotrophin for an in-vitro fertilization programme. Hum Reprod. 1994:9(10):1803-6.

15. Raosoft Sample size calculator. http://www.raosoft.com/samplesize.html. Accessed 3 May 2018.

16. Mansour R, Fahmy I, Tawab NA, Kamal A, El-Demery Y, Aboulghar M, Serour G. Electrical activation of oocytes after intracytoplasmic sperm injection: a controlled randomized study. Fertil Steril. 2009;91(1):133-9.

17. Rockliff HE, Lightman SL, Rhidian E, Buchanan H, Gordon U, Vedhara K. A systematic review of psychosocial factors associated with emotional adjustment in in vitro fertilization patients. Hum Reprod Update. 2014; 20(4):594-613

18. Li XH, Ma YG, Geng LH, Qin L, Hu H, Li SW. Baseline psychological stress and ovarian norepinephrine levels negatively affect the outcome of in vitro fertilisation. Gynecol Endocrinol. 2011;27(3):139-43.
19. Turner K, Reynolds-May MF, Zitek EM, Tisdale RL, Carlisle AB, Westphal LM. Stress and anxiety scores in first and repeat IVF cycles: a pilot study. PLoS One. 2013;8(5):e63743.

20. Nouri K, Litschauer B, Huber JC, Buerkle B, Tiringer D, Tempfer CB. Saliva cortisol levels and subjective stress are not associated with number of oocytes after controlled ovarian hyperstimulation in patients undergoing in vitro fertilization. Fertil Steril. 2011;96(1):69-72.

21. Doldi N, Papaleo E, De Santis L, Ferrari A. Treatment versus no treatment of transient hyperprolactinemia in patients undergoing intracytoplasmic sperm injection programs. Gynecol Endocrinol. 2000;14(6):437-41.

22. Lebedeva IY, Singina GN, Lopukhov AV, Shedova EN, Zinovieva NA. Prolactin and growth hormone affect metaphase-ll chromosomes in aging oocytes via cumulus cells using similar signaling pathways. Front Genet. 2015;6:274.

23. Gonen Y, Casper RF. Does transient hyperprolactinemia during ovarian hyperstimulation interfere with conception or pregnancy outcome? Fertil Steril. 1989;51(6):1007-10.

24. Jinno M, Ubukata Y, Satou M, Katsumata Y, Yoshimura Y, Nakamura Y. A novel method of ovarian stimulation for in vitro fertilization (bromocriptinerebound method) increases developmental potential of oocytes and pregnancy rate. Nihon Sanka Fujinka Gakkai zasshi. 1995;47(12):1337-44.

25. Moride N, Kuwahara A, Yamashita M, Tanaka Y, Matsuzaki T, Yasui T, Irahara M. Does the bromocriptine-rebound method improve embryo quality? J Med Invest. 2011;58(1-2):63-6.

\section{Ready to submit your research? Choose BMC and benefit from:}

- fast, convenient online submission

- thorough peer review by experienced researchers in your field

- rapid publication on acceptance

- support for research data, including large and complex data types

- gold Open Access which fosters wider collaboration and increased citations

- maximum visibility for your research: over $100 \mathrm{M}$ website views per year

At BMC, research is always in progress.

Learn more biomedcentral.com/submissions 